\title{
GÊNERO, MASCULINIDADES E ALCOOLISMO: BRASIL NO INÍCIO DO SÉCULO XX
}

\section{Zulemar Augusta Girotto Savian ${ }^{1}$}

Resumo: A presente pesquisa tem como objetivo analisar, em uma perspectiva das relações de gênero, os discursos masculinos vinculados ao consumo de álcool no Brasil, no inicio do século XX. Através de pesquisa bibliográfica e da análise de propagandas de cerveja da época, busca-se compreender a relação entre a definição de masculinidade e o consumo de bebida alcoólica, e como foi possível a emergência das cervejarias brasileiras em um momento em que o consumo alcoólico passava a ser considerado um problema social e de saúde pública, sob o controle do Estado e do saber médico. O intenso debate sobre a questão do consumo excessivo de bebidas alcoólicas, posto naquele momento, fez com que os fabricantes de cerveja investissem em um novo significado de consumo, distante daquele condenado, na busca do consumidor, em particular, o masculino, das classes mais abastadas. As imagens projetadas nas propagandas estabelecem um perfil idealizado de masculinidade vinculado à elite do sudeste brasileiro, distinto daquele relacionado às classes mais pobres urbanas e vinculado a problemas sociais.

Palavras - chave: alcoolismo, masculinidades, gênero

\section{Introdução}

O tema do alcoolismo, em uma análise de gênero, permite analisar o amplo debate realizado a respeito do assunto no inicio do século XX e a movimentação dos vários setores da sociedade brasileira, em particular do Estado e da medicina higienista, com o mercado cervejeiro, na influência

\footnotetext{
${ }^{1}$ Aluna da Universidade do Sagrado Coração - Bauru.
} 
sobre o controle ou estímulo do consumo de álcool no mercado brasileiro daquele período.

Destaca Carneiro (1994, p. 157) que “a droga como um objeto claro e definido nunca existiu (...) A droga sempre foi um conceito antes de tudo moral”. E é com base nesse valor moral que as sociedades moldamse de diversas formas.

Com base nessas considerações, a presente pesquisa tem como objetivo analisar, em uma perspectiva das relações de gênero, os discursos masculinos vinculados ao consumo de álcool no Brasil, no inicio do século XX. Através de pesquisa bibliográfica e da análise de propagandas de cerveja da época, busca-se compreender a relação entre a definição de masculinidade e o consumo de bebida alcoólica, e como foi possível a emergência das cervejarias brasileiras em um momento em que o consumo alcoólico passava a ser considerado um problema social e de saúde pública, sob o controle do Estado e do saber médico.

Inicialmente, conceitua-se gênero como uma categoria de análise que reivindica para si o território específico na explicação da desigualdade entre o feminino e o masculino. É necessário defini-lo para se compreender os padrões de masculinidades estabelecidos no inicio do século passado, a partir da sua relação com o consumo de bebida alcoólica. Delineia-se um breve parecer sobre a trajetória de gênero enquanto categoria de análise, que se coloca a partir dos anos oitenta e se firma, no Brasil, na virada do século XIX, e seu vínculo com o uso de um amplo leque de fontes e temas pautados pela Escola dos Annales, Teoria crítica marxista, pósmodernismo, dentre outros, em uma análise interdisciplinaridade. A partir da reflexão do gênero como categoria de estudo, pode-se perceber a cons- 
trução de várias concepções de masculinidade agregadas aos discursos alcoolistas do inicio do século XX.

Essas redefinições ocorrem em conjunto às mudanças que ocorrem nas cidades brasileiras a partir do controle do tempo e da monetarização do trabalho, processo que já estava em curso desde o século XIX. A formação de novas classes sociais refletiu na diversificação de vários padrões de masculinidades, construídos a partir das diferenças étnicas e de nacionalidade. Analisa-se as imagens de masculinidade identificadas naquele momento a partir de sua relação com o consumo de álcool e a sua relação com os discursos médicos, pautados na teoria da degenerescência, e as políticas públicas e medidas de controle e tratamento adotadas.

No mesmo período em que se fixavam discursos políticos e médicos que condenavam o consumo em excesso de álcool, em particular da aguardente, vinculando-o à degeneração mental, identifica-se o fortalecimento de uma indústria cervejeira que incentivou, com veemência, o consumo da bebida alcoólica, por meio de ampla difusão de propagandas destinadas e estimular o consumo de cerveja e a conquistar um determinado perfil de consumidor. Pautada na teoria da Eugenia, a associação do álcool à doença degenerativa estava relacionada pelo discurso médico e político às classes mais pobres, enquanto a indústria cervejeira incentivava o consumo controlado da cerveja a grupos das classes médias e altas urbanas.

Posteriormente, foca-se no desenvolvimento do mercado nacional de bebidas alcoólicas do período. Diferente da aguardente, que desde o Brasil Colônia já era uma bebida altamente difundida em todo o território nacional, as cervejarias cresceram principalmente com a imigração, sendo 
responsável pela importação de mão de obra técnica para o fabrico da cerveja no sudeste brasileiro.

Por fim, analisa-se sete propagandas de época da cervejaria Brahma, divulgadas pelo próprio fabricante, entre as quais estão a cerveja Brahma Chopp, cerveja Supimpa, cerveja Teutônia e a cerveja escura Malzbier. Verifica-se nos anúncios e no direcionamento das mensagens, no uso das cores e nas expressões faciais das imagens, a construção de um perfil idealizado de consumidor, em especial o masculino, cujo ato de beber é vinculado com o seu papel social e a sua sociabilidade na região urbana brasileira em maior desenvolvimento industrial e econômico do período.

\section{O Estudo do Gênero}

Inicia-se essa reflexão com a discussão sobre as questões de gênero, conceituando-o enquanto uma categoria útil não apenas à história das mulheres, mas também a outros sujeitos históricos. O gênero pode lançar luz sobre a história das mulheres, assim como a dos homens, das relações entre homens e mulheres, dos homens entre si, e igualmente das mulheres entre si, além de propiciar um campo fértil de análise das desigualdades e das hierarquias sociais (FILHO, 2005).

Os debates voltados à mulher surgiram por volta dos anos sessenta. Com a influência dos movimentos feministas, pesquisadores colocaram em pauta o papel das mulheres na História, procurando compreender as diferenças instituídas entre os sexos e as relações de poder estabelecidas entre eles. Segundo Feitosa (2005) essas discussões feministas vieram 
acompanhadas de uma reelaboração dos princípios teóricos das Ciências Humanas, até então pouco atentos às experiências femininas.

Entretanto, o processo de emergência da categoria gênero deu-se apenas nas últimas décadas do século XX. Com o pressuposto de reintegrar as mulheres à sua história, num primeiro momento as pesquisas priorizaram o tema do trabalho feminino fabril, para depois recuperarem a atuação das mulheres no processo histórico como sujeitos ativos, de modo que as imagens de passividade, ociosidade e confinação ao espaço do lar foram questionadas, descortinando esferas de influência e recuperando os testemunhos femininos. Segundo Matos (1998), os estudos de gênero ampliaram e diversificaram os temas abordados, focalizando diferentes tempos e espaços históricos.

As análises de gênero debruçaram-se sobre um novo leque de fontes e novas concepções teóricas para a produção do conhecimento histórico e acadêmico, pautados na discussão da Nova História, na teoria crítica marxista, no pós-modernismo, em uma análise interdisciplinar (PEDRO, 2005).

Esses estudos incorporaram, mesmo que tardiamente, a questão da violência e do alcoolismo numa perspectiva histórica, aprofundando as investigações sobre o imaginário feminino e masculino. Para que isso fosse possível alargou-se o conceito de documento histórico, com a utilização, além dos tradicionais escritos oficiais, também da música, da literatura, da imprensa, do cinema e dos documentos arqueológicos, entre outros, para "trazer para a História as experiências e os olhares femininos" (FEITOSA, 2005 p. 26). 
O gênero, enquanto categoria de análise, tem o objetivo de propor uma transformação nos paradigmas do conhecimento histórico tradicional, não apenas acrescentando novos temas, mas também impondo um reexame crítico das premissas e dos critérios do trabalho científico existente. Para Scott (1989), ao lado das noções de classe e etnia, o gênero assinala o interesse da historiografia em um contexto que inclua os discursos dos oprimidos, dos silenciados, das feminilidades e masculinidades, numa análise do sentido e da natureza destas considerações.

Em face da quantidade de abordagens existentes, o gênero reivindica para si um território específico para explicar a desigualdade entre mulheres e homens. Como nova categoria de análise, o gênero procura dialogar com outras ciências existentes, tal como a Sociologia e a Antropologia, mas vulgarmente ainda é usado como sinônimo de história das mulheres (PEDRO, 2005). A interdisciplinaridade, segundo Matos (1998), possibilita a analise de manifestações passadas da experiência coletiva e individual de mulheres e homens, destacando-se que o meio social e as experiências sociais são historicamente construídos.

A produção historiográfica sobre o gênero ampliou-se e diversificou-se nos últimos anos. Os estudos sobre a mulher, sua participação na sociedade, na organização familiar, em movimentos sociais e políticos e no universo do trabalho, adquiriram notoriedade e abriram novos espaços na produção acadêmica, num primeiro momento para os estudos vinculados à feminilidade e depois para os “men’s studies”, focados também na masculinidade. Segundo Botton (2007), mesmo com o crescimento da produção historiográfica sobre o gênero nas últimas duas décadas do século XX, ainda são poucos os trabalhos que analisam temas como a mascu- 
linidade ou a homossexualidade, deixando de estudar a pluralidade dos femininos e masculinos e suas intrigantes construções.

Os estudos de gênero estão inseridos no processo de reorganização a certas tendências da historiografia contemporânea, que questiona a concepção de História como uma evolução linear e progressiva do tempo, vinculada a leis de mudanças e prognósticos do futuro. Essa nova perspectiva rompe com a segmentação entre passado e presente. Segundo Matos (1998), contribuem para a ampliação do objeto do conhecimento histórico e levam à descoberta de temporalidades heterogêneas, ritmos desconexos, tempos fragmentados e descontinuidades.

Por fim, os estudos de gênero focalizam a multiplicidade das durações que convivem entre si arraigadas na trama histórica. Dessa forma, as nuanças, tendências e movimentos passam a ocupar a atenção dos historiadores, principalmente no final do século XX e inicio do XXI, no lugar da certeza de fatos cronológicos e periodizações específicas.

Nesse sentido é importante observar que as diferenças sexuais, enquanto construções culturais, linguísticas e históricas, incluem relações de poder não localizadas exclusivamente em um ponto fixo, mas presentes na trama histórica. Para Scott (1989), entender o gênero significa perceber que o mesmo é então uma construção social e não biologicamente definida a partir do nascimento dos seres.

Em relação às definições de masculinidade no início do século XX, no Brasil, considera-se que existiu, ao mesmo tempo, um discurso médico e político, repleto de vozes masculinas, que condenava o consumo de álcool, vinculando-o à degeneração nas classes pobres das cidades, e, em contrapartida, identifica-se o discurso da indústria cervejeira que buscava 
consumidores e procurava incentivar o consumo da cerveja, através dos anúncios vinculados à classe média e alta urbana. A partir dessa reflexão, a proposta desta pesquisa é justamente compreender, através das propagandas de cerveja, como se deu a construção desse novo perfil de masculinidade e sua relação com o consumo de bebidas alcoólicas e o alcoolismo.

\section{Discursos Masculinos e Alcoolismo}

As masculinidades não podem ser estudadas nem entendidas por si só; diversas outras estruturas e instituições sociais devem ser levadas em conta nos estudos sobres os masculinos, como a etnia, a classe social, a nacionalidade, a geração, a temporalidade, a territorialidade, entre diversos fatores relevantes. Segundo Botton (2007), deve-se fugir de qualquer acusação etnocêntrica ou reducionista ao se estudar esse assunto.

A partir da multiplicidade do olhar sobre as masculinidades, encontra-se um terreno fértil para abordagens históricas e interdisciplinares no campo dos estudos masculinos. As masculinidades são configurações práticas das relações de gênero, da mesma forma como estão perpassadas pelas relações de classe social (BOTTON, 2007).

Proponho entendê-las no inicio do século $\mathrm{XX}$, na região sudeste do Brasil e vinculadas à questão do alcoolismo na égide da sociedade burguesa, onde os novos padrões de tempo e trabalho, além de moldarem o comportamento dos indivíduos, contribuíram para a construção de novas identidades, tanto para o feminino quanto para o masculino.

Segundo Cunha (1986), no começo do século passado as noções de tempo e trabalho se consolidavam com mais intensidade, em particular no 
sudeste brasileiro. As antigas vilas do Brasil Colônia, como São Paulo, receberam grande concentração de gente em função da monetarização do trabalho, processo que já estava em curso desde o século XIX. A nova forma de trabalho assalariado engendrou mecanismos de controle para garantir sua funcionalidade ao novo patamar da cidade.

Na última década do século XIX foram consideráveis as mudanças das cidades brasileiras, principalmente na região sudeste. A modernização, unida à grande migração urbana, deu inicio a um novo tipo de cidade, radicalmente diferente da antiga vila brasileira. Em 1890 as cidades já tinham chaminés de fábricas e um movimento mais intenso de circulação de mercadorias (CUNHA, 1986).

A expansão da cidade foi acompanhada pelo rápido crescimento dos serviços urbanos e o proletariado industrial e os demais contingentes populares foram afastados para os bairros cada vez mais distantes. Separou-se o público do privado e consolidou-se um padrão de privacidade familiar, regras, higiene e moralidade.

Segundo Alvim (1998), a configuração do espaço urbano foi o palco das novas relações sociais: primeiro, de produção, em que o assalariamento substituiu a escravidão com base no falso principio da igualdade entre os indivíduos; segundo, da desigualdade social, com a criação de espaços diferentes para classes desiguais, que consequentemente fomentariam percepções de diferentes masculinidades e feminilidades.

Com a nova organização da cidade a burguesia industrial urbana influenciou na criação de novos conceitos de masculino e feminino, na construção de uma imagem do bom trabalhador associada à família e à 
Cadernos de Clio, Curitiba, n. ${ }^{\circ}$ 4, 2013

moral. Segundo Rago (2009), foi necessário o controle do tempo do trabalhador para discipliná-lo às suas funções de proletariado fabril.

Para Cunha, a monetarização das relações de trabalho garantiu uma mão de obra “de baixo custo” aos patrões, e criou, nas cidades, um espaço de concentração de enorme contingente humano de despossuídos, que resistia às margens da sociedade do trabalho:

\begin{abstract}
“Além do desafio de disciplinar estas multidões, com o controle do tempo e do trabalho, havia também uma ameaça a ser esconjurada, e que residia às margens da sociedade do trabalho, corporificada nas figuras dos vadios, dos jogadores, das prostitutas e seus cafetões, dos ladrões, de todos os tipos de desordeiros contidos na população urbana” (CUNHA, 1986,p. 25).
\end{abstract}

Acentua-se a diversidade social da cidade nesse período, com ricos, pobres, classes médias urbanas, fazendeiros industriais, banqueiros, comerciantes, proletários e uma grande massa popular que necessitou se adequar às novas relações de tempo e de trabalho e ao novo modelo moral da família nucleal e higienizada.

Esse conjunto de mudanças caracteriou, além da diversidade social urbana, a existência de quatro padrões principais de masculinidade que estavam atrelados às engrenagens sociais e a construção de gênero do Ocidente. Connell (1995 apud Costa, 1998) identifica como primeiro padrão a masculinidade hegemônica, ligada à legitimidade do patriarcado, que garantia a dominação dos homens e a subordinação das mulheres; é o padrão convencionado pela burguesia elitista.

No segundo padrão, a masculinidade subordinada, Connell (1995 apud Costa, 1998), o caracterizaria como a dominação e a subordinação 
entre grupos de homens da época, como é o caso da dominação dos homens heterossexuais e a subordinação dos homens homossexuais.

O terceiro padrão de masculino estaria representado na masculinidade cumplice, que se definiu pela conexão com o projeto da masculinidade hegemônica, mas sem a completa incorporação do ideal burguês. Teriam sido cúmplices, pois perceberam e desfrutaram de vantagens do patriarcado sem, no entanto, defenderem publicamente essa posição. Geralmente está relacionada a indivíduos das classes médias urbanas.

E, por ultimo, Connell define um quarto padrão de masculino, representado na masculinidade marginalizada, que teria sido próprio das relações entre grupos étnicos, dominantes e subordinados, estes representados pelas classes menosprezadas das cidades, de condição social com menor renda, dos moradores de cortiços e pobres urbanos.

Para Neves (2004), a masculinidade hegemônica exerceu efeito controlador na sociedade brasileira do inicio do século XX e implicou discursos sobre dominação e ascendência social, atribuídos aos homens como “privilégio potencial”.

O padrão de masculino hegemônico construiu um discurso que atribuiu aos homens o privilégio potencial de dominação e ascendência social. Para Almeida (1996), o patriarcado foi uma ordem de gênero específica na qual a masculinidade hegemônica definiu a inferioridade do feminino e das masculinidades subordinadas. As diferentes faces do masculino foram marcadas por assimetrias como heterossexual/homossexual e hierarquias de mais e menos masculino.

Os padrões masculinos são importantes, pois estão ligados ao contexto alcoolista brasileiro dos primeiros anos do século $\mathrm{XX}$, visto que 
existiam discursos masculinos específicos que defendiam ou condenavam o consumo em excesso de álcool. Quando estudados, os padrões masculinos remetem a questões como a identificação de seus discursos alcoolistas e a esfera social a qual se encontravam.

O valor atribuído ao consumo excessivo do álcool, assim como os significados de femininos ou de masculinos, segundo Neves (2004), estão relacionados com as atitudes, normas, modos de classificação e concepções do momento histórico em que são construídos. O uso em excesso das bebidas alcoólicas, para esse autor, corresponde diretamente ao comportamento culturalmente constituído pelos indivíduos em sociedade.

Cada sociedade estabelece os momentos de beber e os diferentes significados atribuídos a esse ato. Na sociedade brasileira do inicio do século XX, os significados culturais ligadas ao consumo do álcool, no tangente ao gênero, estavam relacionadas com uma forma de controle social (NEVES, 2004). Os dois principais padrões masculinos que Connell (1995 apud Costa 1998) salienta como característicos do período são a masculinidade hegemônica e a marginalizada, responsáveis por discursos expressivos sobre a questão do alcoolismo.

Na nova cidade que se formava delinearam-se diferentes significados ä alcoolização, relacionados com as novas classes sociais que se organizavam. Para Savian (2010), nos locais de condição social menos abastada, dos bairros de proletários aos cortiços povoados por ex-escravos, o alcoolismo foi atrelado principalmente ao consumo de aguardente, por seu baixo custo e por sua popularização desde o Brasil Colônia. Nos ricos bairros burgueses localizados em áreas mais nobres da cidade, e nos bairros de uma classe média ascendente, o vinculo com a bebida alcóolica 
estava mais para o consumo de vinho e posteriormente da cerveja. Enfatiza Andrade (2007) que no final do século XIX, além da produção de vinho e da aguardente, instalavam-se no Brasil duas grandes cervejarias, a Brahma, desde 1888, no Rio de Janeiro, e a Antarctica, desde 1889, em São Paulo.

Até o final do século XIX o problema que o excesso do consumo de bebidas alcoólicas poderia gerir nas relações de trabalho não despertava interesse, pois não havia o mesmo rigor de controle de tempo e de trabalho que passou a ser necessário para legitimar a nova configuração da cidade burguesa capitalista.

Para Oliveira (2004), o padrão masculino hegemônico definiu os momentos socialmente aceitos para a alcoolização. Alimentados pelo slogan da medicina higienista "mente sã num corpo são”, o consumo do álcool no espaço público das cidades não foi incentivado pelo discurso médico e político, visto que o consumo de bebidas alcoólicas deveria relacionar-se à socialização e não ao alcoolismo. Se um homem fosse apanhado embebedando-se sozinho, era chamado de alcoólatra. Já o fato de beber em grupo era visto como parte da sociabilidade e de maneira alguma relacionado com o problema do alcoolismo (NEVES, 2004).

O problema do consumo do álcool em excesso ligava-se, segundo Engel (2009), à alienação social. As famílias internavam homens e mulheres em hospícios, quando descoberto que a pessoa sofria do mal do alcoolismo, pois, sendo alcoólatra, essa pessoa deveria ser retirada do seio social e estar reclusa para tratamento.

A prescrição médica dos hospícios em relação aos alcoólatras é característica nos laudos médicos, como nesse trecho: “(...) não encontrando 
um meio de se adaptar a sociedade, acham no suicídio uma saída; outros, num suicídio lento, lançando-se ao abuso do álcool, disfarçam na embriaguez as ideias tristes (...)” (CUNHA, 1986, p. 52-3).

Aliado ao progresso da modernidade, às novas formas de trabalho urbano e à disciplinarização do trabalhador, a cidade revelou sérios problemas sociais vinculados ao consumo excessivo de álcool. Fez-se necessário a consolidação de um saber médico higienista, apoiado pelo discurso masculino hegemônico, pelas teorias eugênicas e pelo poder médico, como instituição voltada à assistência dos “enfermos da razão”, para vincular o alcoolismo à doença social e mental.

Segundo Cunha (1986), a medicina higienista, aliada a todo um conjunto de instituições, não mediu esforços em direção a edificação de uma cidade considerada higiênica, "livre da peste e do perigo”, que conseguisse reproduzir em seu interior uma imagem ideal vitoriosa da ordem burguesa. A medicina social, higienista, autorizada por seu caráter científico tendeu a "construir um discurso sobre todas as instâncias da vida, invadindo a esfera das relações pessoais para moldá-las segundo os propósitos da ordem e da disciplina urbanas” (CUNHA, 1986, p. 35).

A teoria da Eugenia idealizava o controle social através de um embranquecimento da população brasileira, com perseguição, em especial, àqueles considerados genética e moralmente propensos à degeneração, como os negros, mestiços, prostitutas, homossexuais, alcoólatras e portadores de deficiências físicas ou mentais.

Para Miskolci (2006), o discurso da medicina higienista, aliado a Eugenia, remeteu a um projeto político-social apoiado em sua suposta cientificidade para justificar e implantar práticas sociais de controle no 
inicio do século XX. Em 25 de janeiro de 1918 foi criada a Sociedade Eugênica de São Paulo, a primeira organização do tipo na América Latina a apoiar a Teoria da Eugenia. Entre seus sócios estavam médicos influentes como Renato Kehl e o Dr. Mancorvo Filho, e entre seus admiradores figuravam intelectuais como Monteiro Lobato.

A associação do alcoolismo às classes mais pobres urbanas, realizada pelos adeptos da Eugenia, reforçava o necessário controle dessa população e o seu enquadramento ao novo perfil de trabalhador exigido no interior da nova ordem social. Santos e Verani (2010) consideram que a medicina higienista, aliada aos conceitos eugenistas, tenha se preocupado com os danos que o uso abusivo de bebidas alcoólicas pudesse causar no organismo como um todo, de problemas gastrointestinais, renais ou insuficiência hepática, mas principalmente com os danos sociais. Para os autores, o foco principal da psiquiatria era os distúrbios mentais e morais tidos como anormalidades sociais.

Sob a influência da Teoria Eugênica, a medicina higienista levou à internação, em hospitais psiquiátricos, pessoas consideradas socialmente doentes. Segundo Miskolci (2006), fomentou-se procedimentos de perseguição e controle da população mais pobre que não se ajustou ao padrão de comportamento e trabalho imposto pela ordem burguesa, problemas que, na verdade, só poderiam ser resolvidos por meio de transformações econômicas e sociais profundas.

As técnicas mais conhecidas de "aprimoramento da raça” foram adotadas pelos adeptos da eugenia mendeliana: as esterilizações, a segregação sexual compulsória, a eutanásia, o vinculo da influência do álcool com a degenerescência, isto é, seriam alcoólatras filhos de pais alcoóla- 
Cadernos de Clio, Curitiba, n. ${ }^{\circ}$ 4, 2013

tras, e o vinculo da homossexualidade à doença mental (MISKOLCI, 2006).

Os médicos adeptos da Eugenia também difundiram modelos evolucionistas para justificar que a diferença entre os sexos confirmava uma estrutura natural na delimitação das relações sociais. Combateram a difusão e o consumo em excesso do álcool como medida de profilaxia social (JUNIOR e LOVISOLO, 2003).

Segundo Soihet (2009), a medicina social eugênica assegurava como características femininas, por razões biológicas, a fragilidade, o recato, o predomínio das faculdades afetivas sobre as intelectuais e a subordinação da sexualidade à vocação maternal. Em oposição, o homem era caracterizado por sua força física, natureza autoritária, empreendedora, racional e uma sexualidade sem freios.

O alcoolismo feminino também despontou nesse contexto, Santos e Verani (2010) analisam que pela ótica da medicina higienista as mulheres que se alcoolizavam, mesmo dentro dos lares, descumpriam seu papel de ponto de equilíbrio moral e emocional da família e faltavam com o seu dever de mãe. Segundo os parâmetros médicos vigentes, a fragilidade do organismo feminino diante do álcool representava um perigo na concepção de filhos que geneticamente herdariam a "tara alcoólica”.

A forte tendência do "mal do alcoolismo" pode ser vista no discurso do médico higienista Cunha Cruz:

(...) é digno de atenção o número que indica a proporção de mulheres com perturbações mentais, devidas ao alcoolismo, em nossos hospícios e colônias. A proporção é tão grande que difícil é encontrar igual em estatísticas, mesmo nos países mais alcoolizados - 
nós, pelo menos, não conhecemos igual. (CUNHA CRUZ, 1906, p.14 apud SANTOS; VERANI, 2010, p. 406).

Destacam Santos e Verani (2010) que o fator hereditário delimitaria uma pré-disposição que levaria ao excesso do álcool. Dessa forma, o hábito de beber apenas moderada e socialmente se transformaria em uma moléstia na qual o costume se tornaria uma necessidade orgânica. A medicina higiênica, aliada à teoria da Eugenia, colocaria a obsessão pelo álcool como doença degenerativa, capaz de levar a pessoa a cometer atos insanos e descontrolados e a apresentar comportamentos condenáveis do ponto de vista da sociedade da época.

O alcoolismo também estava presente com frequência no contexto da época, e com relação ao homem pobre, representante do padrão masculino marginalizado, Soheib (2009) enfatiza que o homem pobre, por suas condições de vida, estava longe de assumir o papel de mantenedor da família previsto na ideologia dominante e tampouco o papel de dominador, típico do padrão hegemônico. Na medida em que a prática de vida do homem pobre revelava uma situação bem diferente daquela idealizada pela hegemonia, o álcool era visto como válvula de escape aos problemas e solução para a insegurança que muitas vezes os acometia.

Analisa a autora que a violência doméstica decorrente do alcoolismo surgia da incapacidade desse homem pobre de exercer o poder irrestrito sobre a mulher, como ocaso apresentado abaixo:

Constata-se que à medida que Marcolino (o marido) mergulhava na bebida, era rejeitado cada vez mais pela sociedade e, por isso, tinha necessidade de se reassegurar de sua autoridade junto à família. $\mathrm{O}$ que fazia tentando obrigar Arminda (a esposa) a atitudes extrava- 
gantes, como a prática de atos sexuais na frente dos filhos. Espancando-a, também buscava demonstrar que no interior do seu lar ele deveria afigurar-se como todo poderoso (SOHEIB, 2009, p. 372).

Além dos discursos da medicina higienista pautados na Eugenia, existiram outras vozes masculinas, principalmente na esfera da política, que se remetiam ao tema, numa tentativa de influenciarem o controle e a distribuição de bebidas para se reduzir o consumo excessivo de álcool.

Encontra-se em Marques (2007) um desses discursos políticos. Juvenal Lamartine, deputado eleito pelo Rio Grande do Norte, propôs a resolução do que via como problema nacional da época. Em uma sessão de 1917 sugeriu aumentar em três vezes o valor do imposto que incidia sobre a aguardente e o vinho de consumo popular, conclamando seus colegas a legislarem em favor da população:

Nada temos feito até agora no sentido da defesa da nossa população contra o alcoolismo (...) enfraquecida nos seus elementos componentes, nos seus alicerces fundamentais, e cuja principal causa devemos ir buscar no abuso do álcool o grande número de desequilibrados que enchem os hospitais, a tuberculose que devasta a nossa população operária, as moléstias do fígado, dos rins, o envelhecimento prematuro das artérias tão frequente no Brasil são, na sua maioria, efeitos de uma só causa: o álcool. (LAMARTINE, 1917, Diário do Congresso Nacional, apud, MARQUES, 2007, p.45).

Lamartine legislava a favor da proibição em todo o território nacional, da importação e da fabricação de qualquer bebida com teor alcoólico superior a $2 \%$, o que eliminaria do mercado todas as bebidas destiladas, especialmente a aguardente, o que para ele (como adepto da temperança) era o grande mau das massas urbanas mais pobres. 
Foi da criação de Lamartine um projeto de lei que propunha que se uma pessoa, independente da etnia ou classe social, fosse encontrada bêbada na rua, seria recolhida à prisão pelo prazo de dez dias, além de ser multada em 200\$000 (duzentos mil réis). Reincidentes pagariam o dobro. E no caso do embriagado ser funcionário público a situação se agravaria ele poderia ser demitido, a bem da moralidade pública, e ficaria impossibilitado de exercer função no Estado por dez anos (MARQUES, 2007).

Mesmo que Lamartine vivesse fosse um representante do padrão masculino elitista, moralmente aceito pela sociedade então vigente, suas propostas implicariam em uma reviravolta no mercado externo e interno da produção de bebidas alcoólicas brasileira. Quase todos os seus projetos relacionados à proibição do consumo de álcool, segundo Marques (2007), não foram aprovados, mas tiveram uma repercussão de grande importância na imprensa da época, em jornais como O Jornal do Brasil e O Diário do País.

A análise de os projetos de lei como os do deputado Lamartine ou das teorias da Eugenia e da medicina higienista possibilita considerar como era construído o pensamento médico e político da época, que passa a considerar o consumo em excesso do álcool como problema social.

Enquanto esses fortes discursos políticos e médicos veiculavam oposição ao consumo excessivo de bebidas alcoólicas, agregando-o à degeneração mental e ao consumo massivo da aguardente pela população mais pobre, de outro lado vê-se a consolidação da indústria cervejeira que, necessitada de consumidores, investia em fortes campanhas para incentivar o consumo dessa bebida alcoólica, em particular os das classes médias e altas urbanas. O objetivo da indústria cervejeira era simples: a difusão do 
consumo da cerveja para uma parcela específica da população, a elite. Analisa-se a seguir os conteúdos das propagandas veiculadas por cervejarias nacionais do período e as relações de gênero nelas apresentadas.

\section{O Gênero e a Indústria Cervejeira}

A cidade de São Paulo de 1872 é um pequeno entreposto comercial e centro de negócios onde os escravos passavam com latas de excrementos das latrinas das casas senhoriais para despejar nos rios, a água era buscada nos chafarizes e na qual ainda não existia o bonde puxado por burros (ROLNICK, 1983, p. 111 apud CUNHA, 1986).

Sua população subiu de 30 mil pessoas, em 1872, para 357.324 mil, em 1910. Esse crescimento acelerado teve como fundamento a rápida industrialização e a imigração massiva que transformou a pacata vila em uma espécie de “super cidade”, repleta de línguas e culturas diferentes e sobretudo povoada por imigrantes europeus (CUNHA, 1986).

A partir de 1850 a imigração brasileira cresceu em larga escala pela drástica situação em que a Europa se encontrava. O processo de transformação para uma economia capitalista promoveu a concentração de terras nas mãos de poucos proprietários. As altas taxas de impostos para a propriedade dificultaram o pequeno proprietário europeu de efetuar empréstimos e ocasionaram seu endividamento. Havia a oferta de produtos a preços inferiores no mercado e a transformação da mão de obra rural em mão de obra industrial na Europa. Como causas da imigração Alvim (1998) relaciona o alto crescimento demográfico europeu, a falta de empregos e a miséria, aliados ao imaginário positivo sobre a América. 
De 1830 a 1930 o processo de imigração para o Brasil teve em seus primeiros cinquenta anos uma política de translado voltada para a ocupação e o povoamento de extensas regiões, em particular no sul do Brasil. Segundo Foot e Leonardo (1982), nos últimos cinquenta anos do processo houve interesse dos cafeicultores paulistas por mão de obra farta e barata para suas plantações, sobretudo a partir de 1884, visto que a abolição da escravatura era eminente.

Desde meados do século XIX o governo brasileiro procurou atrair milhares de imigrantes europeus para trabalhar tanto na lavoura de café quanto nas fábricas que surgiam nas cidades, substituindo a mão de obra escrava. Segundo Rago (2009), entre 1880 a 1930 entraram no país cerca de 3,5 milhões de imigrantes. Um terço deles de italianos, 1 milhão de portugueses, 560 mil espanhóis, mais de 112 mil alemães, 108 mil russos e 79 mil australianos.

A história da imigração brasileira está diretamente ligada à produção de bebidas alcoólicas do inicio do século passado. Além de suprir a necessidade de mão de obra para o campo, forneceu profissionais técnicos para a cidade, especializados em profissões pouco conhecidas como o manejo das bebidas alcoólicas, exclusivo a uma pequena parcela de trabalhadores dos engenhos de cana-de-açúcar na produção da aguardente. Tem-se registro em propagandas de periódicos da época, como o Almanack Laemmert (1900), que as primeiras cervejarias em território nacional foram fundadas por imigrantes europeus, principalmente alemães. Foram esses imigrantes que trouxeram os mestres cervejeiros munidos da técnica para fabricação nacional da cerveja (SAVIAN, 2010). 
A aguardente era a bebida alcoólica mais consumida em território brasileiro desde o Brasil Colônia. Sua produção estava intimamente ligada à escravidão e boa parte circulava entre a exportação e o comércio interprovincial. Segundo Andrade (2007), no do Rio de Janeiro, no final do século XIX, havia 253 alambiques funcionando, dos quais 155 ficavam na cidade litorânea de Paraty, no Estado do Rio de Janeiro.

Por se tratar de uma bebida altamente difundida entre a população de renda mais baixa, a propaganda em torno da aguardente tornou-se negativa no inicio do século passado, justamente porque nesse período os ideais eugênicos de degeneração da raça e o gosto por produtos e modas que vinha da Europa influenciavam as classes mais abastadas das cidades em ascensão. Com a imigração a partir da década de 40 do século XIX houve uma variação nessa hegemonia e um desenvolvimento urbano no fabrico e consumo da cerveja nas principais cidades. É de se observar que num primeiro momento esse público consumidor era formado, em sua maioria, por uma classe média ascendente das cidades em expansão (SAVIAN, 2010).

O Almanak Laemmert, (analisado por Savian, 2010) periódico publicado no Rio de Janeiro entre de 1844 até 1912 pelos irmãos Eduard e Heinrich Laemmert, registrou mais de vinte produtores de cerveja só em 1888. Boa parte dos produtores de cerveja, segundo os dados do Almanak, era de origem estrangeira e dos exemplos das novas fábricas cervejeiras pode-se citar as três mais conhecidas da época: $1^{\mathrm{a}}$ ) A cervejaria Henrique Leiden e Cia, que fundou a Imperial Fábrica de Cerveja Nacional, na cidade do Rio de Janeiro. $2^{\mathrm{a}}$ ) A Cervejaria Brahma, fundada em 1888, também na cidade do Rio de Janeiro, por um imigrante suíço, Joseph Villiger, 
que crescia abruptamente e se fundia com outras empresas. Já em 1904 sua produção de chope em tonéis chega a seis milhões de litros e a distribuição conta com nove depósitos situados no centro. $3^{\mathrm{a}}$ ) A Cervejaria Antarctica, com fundação na cidade de São Paulo, por Antonio e Helena Zerrener, imigrantes alemães que a transformaram em uma companhia com sessenta e um acionistas já em 1889 e sua capacidade de produção era de quarenta mil hectolitros/ano.

O aumento do numero de fábricas cervejeiras intensificou a divulgação de anúncios publicitários com apelos específicos a um público consumidor urbano: homens e profissionais liberais como advogados, professores, jornalistas, capitalistas e comerciantes médios.

Da mesma forma que cresciam os anúncios cervejeiros, crescia um discurso médico eugenista agregado ao padrão de masculinidade hegemônico, que pregava o controle dos elementos considerados degenerados e perturbadores da ordem social, tendo como foco os negros, os mestiços, as prostitutas e os alcoólatras, entre outros (ALMEIDA, 1996). Os ideais eugenistas e patriarcais podem ter influenciado anúncios de algumas cervejarias. Como veremos a seguir não se encontra nas propagandas de época versões de padrões considerados marginalizados, negros(as), mestiços(as) ou elementos considerados inapropriados pelo discurso masculino hegemônico.

Todos os folders que seguem foram retirados do site da cervejaria Brahma e da Casa do Folder. Eram propagandas dirigidas ao público brasileiro, segundo o próprio fabricante, por volta das primeiras décadas do século passado. A linguagem publicitária é carregada de ideologias, além da preocupação com os aspectos comerciais do produto. Todas as propa- 
Cadernos de Clio, Curitiba, n. ${ }^{\circ}$ 4, 2013

gandas estão em consonância com o contexto histórico do inicio do século $\mathrm{XX}$ brasileiro ao qual se inseriam.

Na análise dos anúncios nota-se que há predominância de imagens de homens da cor de pele branca, com características de pessoas de meia idade, com trajes limpos e cabelos curtos, que expressam um estereótipo especifico de homem patriarcal burguês almejado socialmente no inicio do século XX.

O sorriso na face dos homens e mulheres expressa a satisfação que sugere o consumo da cerveja Brahma. Nas figuras 1, 2, 4, 5, 6 e 7, o copo com a cerveja tem destaque especial. Representado pela cor amarela específica da cerveja clara, está sobreposto em fundos azuis ou brancos que o destacam no folder chamando sua atenção. Pode-se associar o tom amarelo da cerveja ao ouro, à riqueza, ao esplendor, à iluminação solar e à vida nova (CIPOLLA, 2012).

Outro fato de importância na análise das propagandas é a ausência de pessoas vinculadas a padrões considerados “perturbadores” pela nova ordem social burguesa. Nelas não aparecem mestiços (as), negros (as), indígenas ou mulheres com trajes sensuais; em todas as imagens são representadas pessoas que expressavam a legitimidade hegemônica burguesa, industrial, fabril do sudeste brasileiro e isto denota que o marketing cervejeiro estava focado nesse público específico.

Os folders sugerem às pessoas da época o prazer e a sociabilidade do consumo desse produto, como indicam os slogans da Figura 1: “O melhor da Festa!” ou na Figura 4: “Ao Prazer!” ou ainda na Figura 5: “É seu prazer”. 
Na figura 3, o folder da cerveja Malzbier da Brahma coloca a propriedade nutricional desse produto como complemento às refeições. A cerveja escura foi considerada um produto mais leve, portanto, de consumo apropriado pelo público feminino e a ele mais intensamente direcionado.

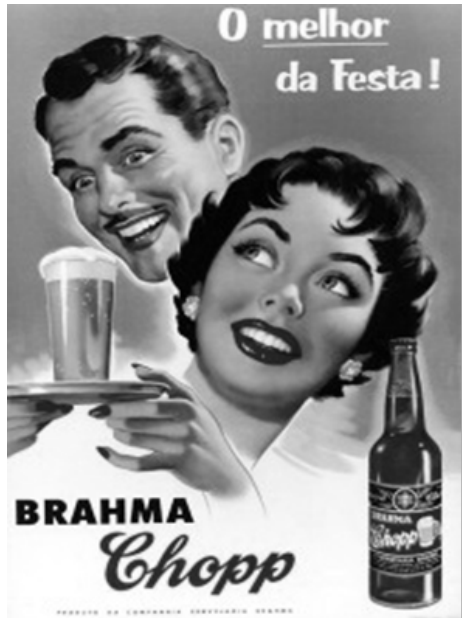

Figura 1: Anúncio dos anos 30. Cerveja Brahma.

Disponível em: www.brahma.com.br

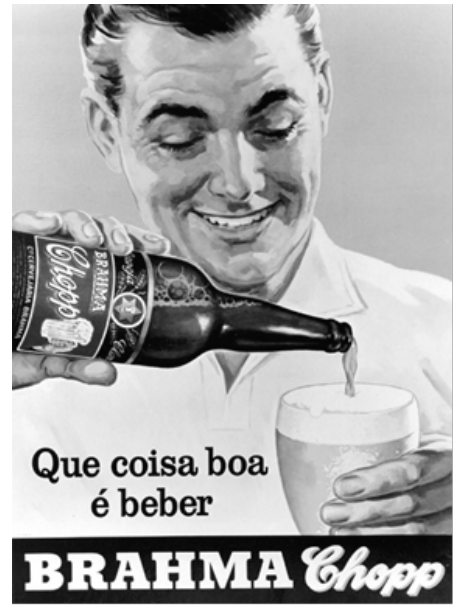

Figura 2: Anúncio dos anos 30 Cerveja Brahma

Disponível em: www.brahma.com.br 
Cadernos de Clio, Curitiba, n. ${ }^{\circ}$ 4, 2013

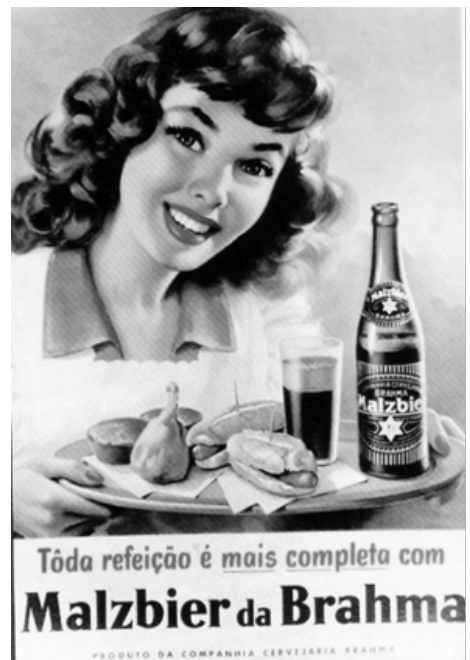

Figura 3: Anúncio dos anos 30. Cerveja Malzbier.

Disponível em:

www.casadofolder.com.br

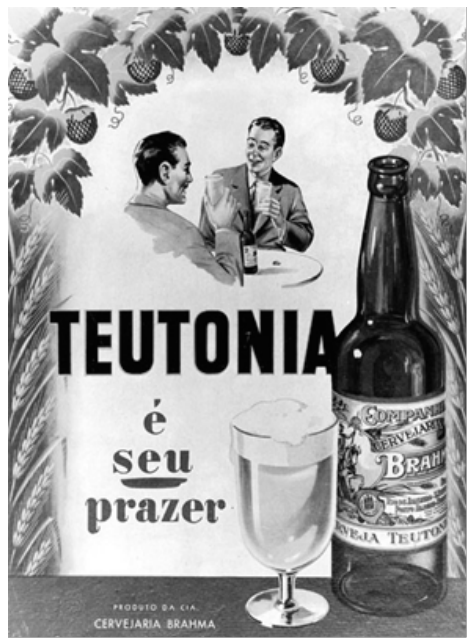

Figura 5: Anuncio dos anos 30 Cerveja Teutônia

Disponível em: www.brahma.com.br

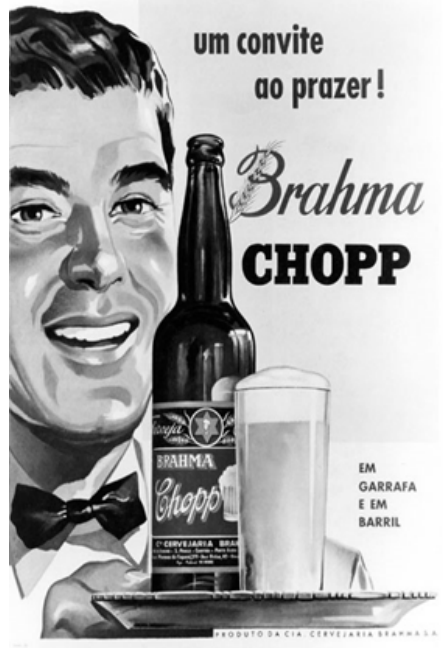

Figura 4: Anuncio dos anos 30 Cerveja Brahma

Disponível em: www.brahma.com.br

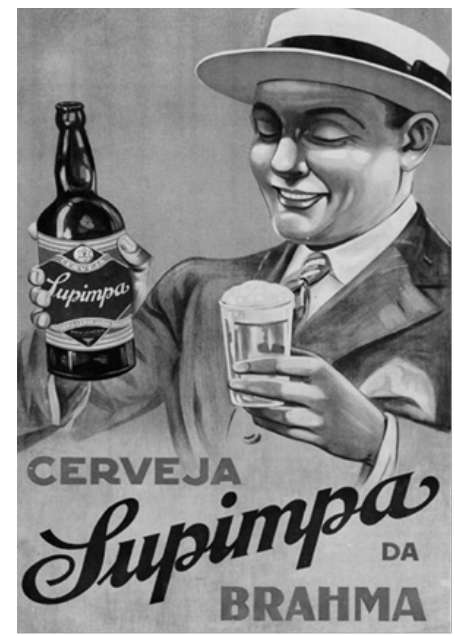

Figura 6: Anuncio dos anos 30 Cerveja Supimpa

Disponível em: www.brahma.com.br 


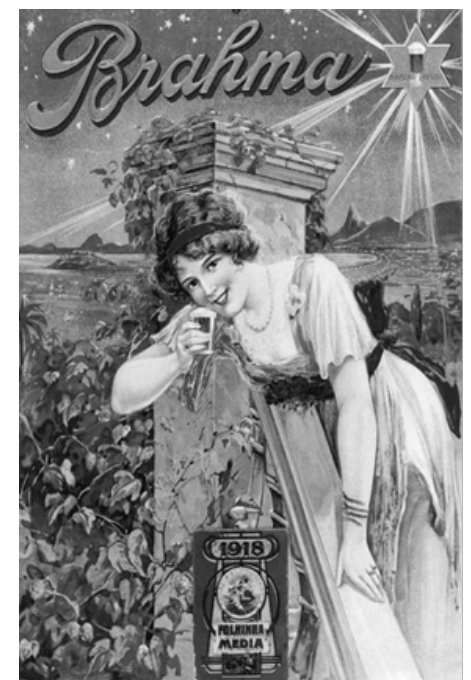

Figura 7: Anuncio de 1918 da Cerveja Brahma Disponível em: www.brahma.com.br

Além de folders como o da Figura 3, encontramos anúncios em jornais de época como O Jornal A Província de São Paulo (hoje o Estadão), que sugeria a difusão da cerveja preta como beneficio à saúde para as mães que amamentavam seus bebes. A cerveja preta, nesse período, começa a ser representada como fonte necessária para uma vida mais saudável para as donas de casa que habitavam as cidades (MARQUES, 2007).

É interessante observar como estas propagandas divulgavam uma imagem de prazer ou saúde associada ao consumo da cerveja, em contraposição ao discurso médico e político, que caracterizava o consumo do álcool como um passo para o alcoolismo, como ressaltado anteriormente.

No que tange as relações de gênero, verifica-se na análise das figuras que a divisão dos públicos consumidores reforçava a ideia difundida pela medicina social eugênica, que assegurava como características femininas a fragilidade, o recato, o predomínio das faculdades afetivas sobre 
as intelectuais, a subordinação da sexualidade e a vocação maternal. Em oposição, o homem conjugava à sua força física uma natureza autoritária, empreendedora, pública, racional e a um forte desempenho sexual.

Com base nessas considerações, percebe-se que o ideal de homem da elite do sudeste brasileiro era aquele de pele branca e possivelmente representante de um padrão masculino convencionado, relacionado ao prazer de beber cerveja em anunciadas festas, na descontração da esfera pública.

Com relação às mulheres, observa-se que também são brancas e possuem características de uma classe social mais elevada, com roupas finas, penteados, batom e unhas em tons avermelhados difundidos pela moda burguesa urbana da época. Para ela o consumo da cerveja estava vinculado à privacidade do lar. Encontra-se em anúncios de periódicos da época, que a associação entre saúde e ingestão da cerveja escura, na hora das refeições, influenciaria no bem estar físico feminino e na boa lactação de sua prole. Não houve vínculo ao prazer, às festas e à liberdade como nos anúncios voltados ao público consumidor masculino.

Pode-se confirmar que a diferença entre homens e mulheres expressa nas imagens das propagandas foi algo que contribuiu, juntamente com os demais elementos sociais, para a confirmação de parâmetros de comportamento feminino e masculino da elite do sudeste brasileiro, e de sua relação de poder sobre outros grupos sociais, em particular das classes populares do inicio do século XX. 
Cadernos de Clio, Curitiba, n. ${ }^{\circ}$ 4, 2013

\section{Considerações Finais}

Pode-se afirmar que houve um intenso debate sobre a questão do alcoolismo no início do século passado. Ao inseri-lo na categoria de análise de gênero, constata-se que existiram diferentes pontos de vista masculinos, médicos, políticos, sobre o consumo excessivo do álcool, que influenciaram na criação de padrões elitistas de consumo para homens e mulheres da cidade urbana brasileira, nos primeiros anos do século XX.

Por um lado existiam os discursos políticos e médicos que veiculavam o consumo excessivo de bebidas alcoólicas ao consumo da aguardente pela população mais pobre. De outro lado consolidava-se a criação de uma indústria cervejeira, necessitada de consumidores, que incentivava o consumo da cerveja, e não media esforços para conquistar cada vez mais consumidores das classes médias e altas urbanas. A alternativa encontrada diante dessa situação conflituosa foi relacionar o consumo da cerveja ao espaço harmônico da sociabilidade, da diversão e da responsabilidade na moderação de seu consumo.

Através da análise das propagandas de cerveja conclui-se que existiram construções culturais, linguísticas e históricas de padrões de comportamento vinculadas ao consumo de cerveja, direcionadas, em particular, para o homem branco das classes médias e altas do sudeste paulista, no inicio do século XX, em uma clara distinção ao consumo da aguardente, particularmente relacionada ao vício, à desordem e ao desajuste social do homem pobre.

Não se pode afirmar que esses conceitos preconizados como hegemônicos pela elite branca do sudeste brasileiro eram os únicos, pois, desta forma, negaríamos toda a história dos embates sociais das populações 
mais pobres, dos negros, dos índios, das mulheres e dos excluídos de maneira geral.

Devemos, pois, nos preocupar em localizar esses conceitos conforme sua época e os grupos sociais em que foram construídos. Faz-se necessário outras pesquisas que apresentem um panorama das opiniões dos diversos grupos envolvidos com a questão do alcoolismo, a fim de ampliar os olhares e as memórias sobre essa questão da história do Brasil.

\section{Referências Bibliográficas}

ALMEIDA, Miguel Vale de. Gênero, Masculinidade e Poder: revendo um caso do sul de Portugal, Anuário Antropológico, Rio de Janeiro, no 95, 1996, p. 161190. Disponível em:<http://site.miguelvaledealmeida.net> acesso: 10/04/2012.

ALVIM, Zuleika. Imigrantes: a vida privada dos pobres do campo_In: SEVCENKO Nicolau (org) História da Vida Privada no Brasil 3 - Republica da Belle Époque à Era do Rádio, São Paulo: Companhia das Letras, 1998, p. 217287

ANDRADE, Eduardo La Regina. Pinga ou Cachaça, 2007. Disponível em:< http://www.paraty.tur.br/> acesso: 28/05/2012.

BETTI, M L. Casa do Poster, 2012. Disponível em: <http://www.casadoposter.com.br> acesso: 15/04/2012.

BOTTON, Fernando Bagiotto. As Masculinidades em questão: uma perspectiva de construção teórica, Revista Vernáculo, no 19 e 20, 2007, p. 109-120. ISSN 1677-0196.

Disponível

em: $<$ http://ojs.c3sl.ufpr.br/ojs2/index.php/vernaculo/article/view/20548/13731>acess o: $10 / 04 / 2012$

CARNEIRO, Henrique. Filtros, mezinhas e triacas: as drogas no mundo moderno. São Paulo: Ed. Xamã, 1994, p. 157.

CIPOLLA, Marcelo Brandão (tradução). Sinais e Símbolos: guia ilustrado das origens e dos significados, São Paulo: Editora WMF Martins Fontes, 2012, 351 p. 
COSTA, Rosely Gomes. De Clonagens e de Paternidades: as encruzilhadas do gênero, Cadernos Pagu (online), vol. 11, 1998, p. 157-199. Disponível em: $<$ http://www.pagu.unicamp.br/node/39>acesso: 10/04/2012.

CUNHA, Maria Clementina Pereira. O Espelho do Mundo: Junquery, a história de um asilo, Rio de Janeiro: Paz e Terra, 1986, p. 21-53.

ENGEL, Magali. Psiquiatria e Feminilidade__In PRIORE, Mary Del (org) História das Mulheres no Brasil, 3 edição, São Paulo: Contexto, 2009, p. 323-359.

FEITOSA, Lourdes Conde. Amor e Sexualidade: o masculino e o feminino em grafites de Pompéia, São Paulo: Annablume, FAPESP, 2005, 165 p.

FILHO, Amilcar Torrão. Uma Questão de Gênero: onde o masculino e o feminino se cruzam, Cadernos Pagu (online), vol. 24, 2005, p. 127-152. Disponível em: http://www.scielo.com.br/pdf/cpa/n24/n24a07.pdf acesso: 10/04/2012.

FOOT, F e LEONARD, V. História da indústria e do trabalho no Brasil: das origens aos anos vinte, São Paulo: Global, 1982, p. 109-127.

JUNIOR, E. G. e LOVISOLO, H. R. Descontinuidades e Continuidades do Movimento Higienista no Brasil do século XX, Revista Brasileira de Ciência e Esporte (online), vol. 25, $\mathrm{n}^{\circ}$ 1, set. 2003, p. 41-54. Disponível em: <http://www.rbceonline.org.br/> acesso: 28/05/2012.

LAEMMERT, Eduard e Heinricht. Almanak Laemmert 1844-1889, Biblioteca Nacional Digital, Disponível em: <http://bndigital.bn.br/periodico > acesso: 28/04/2012.

MARQUES, Teresa Cristina de Novaes. Cerveja e aguardente sob o foco da temperança no Brasil no início do século XX, Revista Eletrônica de História do Brasil (online), Juiz de Fora, vol. 9, $\mathrm{n}^{\circ}$ 1, jan.-jun. 2007. Disponível em:<http://www.rehb.ufjf.br> acesso: 28/04/2012.

MATOS, Maria Izilda S. Estudos de Gênero: percursos e possibilidades na historiografia contemporânea, Cadernos Pagu (online), vol. 11, 1998, p. 67-75. Disponivel em: <http://www.paguunicamp.br/node/39 acesso: 10/04/2012.

MISKOLCI, Richard. A Hora da Eugenia: Raça, Gênero e Nação na América Latina_In: Stepan N L (org) Coleção História e Saúde (online), Rio de Janeiro: Editora Fiocruz; 2006, 228 p. ISBN: 85-89697-05-3. Disponível em: $<$ http://www.scielo.com.br> acesso: 28/04/2012.

NEVES, Delma Pessanha. Alcoolismo: acusação ou diagnóstico? Cadernos de Saúde Pública (online), Rio de Janeiro, vol. 20, n 1, jan. - fev. 2004, p. 7-36. ISSN 0102-311X. Disponível em: <http://www.scielo.br/pdf/csp/v20n1/02.pdf acesso: 10/04/2012. 
OLIVEIRA, Pedro Paulo de. A Construção Social da Masculinidade, Belo Horizonte: Editora UFMG/ Rio de Janeiro: IUPRJ, 2004, 347 p. Disponível em:

$<$ http://www.books.google.com.br> acessado: 05/03/2012.

PEDRO, Joana Maria. Traduzindo o Debate: o uso da categoria gênero na pesquisa histórica, Revista História (online), São Paulo, v. 24, n 1, 2005, p. 77-98. ISSN 0101-9074. Disponível em: <http://www.scielo.br/pdf/his/v24n1/a04v24n1.pdf> acessado: 05/03/2012.

RAGO, Margareth. Trabalho Feminino e Sexualidade_ In PRIORE, Mary Del (org) História das Mulheres no Brasil, 3 edição, São Paulo: Contexto, 2009, p. 581-605.

SANTOS, Fernando Sergio Dumas dos e VERANI, Ana Carolina. Alcoolismo e Medicina Psiquiátrica no Brasil do inicio do século XX, Revista História, Ciência e Saúde (online), Manguinhos, v. 17, supl. 2, dez. 2010, p. 401-420. Disponível em: http://www.scielo.br/pdf/hcsm/v17s2/08.pdf acessado: 10/04/2012.

SAVIAN, Zulemar Augusta Girotto. Alcoolismo na sociedade brasileira no inicio do século XX__In: III Simpósio Internacional de Linguagens Educativas: Educação Mídia e Cultura, Anais... Bauru: USC, mar. 2010, 401 p. Disponível em: $<$ http://www.usc.br/biblioteca/> acesso: 15/03/2012.

SCOTT, Joan. Gender: Na Useful Category of Historical Analyses: gender and the politics of History, New York: Columbia University Press, 1989.

SOIHET, Rachel. Mulheres Pobres e Violência no Brasil Urbano_ In PRIORE, Mary Del (org) História das Mulheres no Brasil, 3 edição, São Paulo: Contexto, 2009, p. 363-399. 